\title{
Anesthetic management of laparoscopy- assisted total proctocolectomy in a cardiac sarcoidosis patient with a cardiac resynchronization therapy-defibrillator: a case report
}

Yutaro Kammura', Ai Fujita ${ }^{2 *}$, Yuji Karashima ${ }^{2}$, Shoko Nakayama ${ }^{2}$, Kazuhiro Shirozu ${ }^{3}$, Tadashi Kandabashi ${ }^{4}$ and Ken Yamaura ${ }^{3}$

\begin{abstract}
Background: Cardiac sarcoidosis (CS) causes severe conduction abnormalities and arrhythmias. CS patients are increasingly being treated with cardiac resynchronization therapy-defibrillators (CRT-Ds). For the first time, we report the anesthetic management of a CS patient with a CRT-D.

Case presentation: A 65-year-old male with an implanted CRT-D due to CS was scheduled for a laparoscopyassisted total proctocolectomy for his transverse colon cancer. His left ventricular ejection fraction was 32.0\%, and his physical status was a New York Heart Association class III. General and epidural anesthesia were performed while using standard monitors and a FloTrac ${ }^{\text {TM }}$ system. The dual-chamber pacing (DDD) modality of the CRT-D was unchanged, and its defibrillation function was deactivated before surgery. The surgery was successfully performed, and the patient was discharged without worsening of his cardiac condition.
\end{abstract}

Conclusions: A detailed understanding of this patient's condition, as well as sarcoidosis, helped to facilitate successful anesthetic management of this patient.

Keywords: Cardiac sarcoidosis, CRT-D, Anesthetic management

\section{Background}

Sarcoidosis is a multisystem disorder of unknown etiology characterized by a non-necrotizing granulomatous inflammation [1]. Symptomatic cardiac involvement is reported in approximately $5 \%$ of patients with sarcoidosis $[2,3]$. The three main manifestations of cardiac sarcoidosis (CS) are conduction abnormalities; ventricular arrhythmias, including sudden cardiac death; and heart failure [2-4]. While implantable cardioverter-defibrillators (ICDs) are

\footnotetext{
* Correspondence: ai-fuji823@hotmail.co.jp

${ }^{2}$ Operating Rooms, Kyushu University Hospital, Maidashi 3-1-1, Higashi-ku, Fukuoka 812-8582, Japan

Full list of author information is available at the end of the article
}

recommended for the treatment of arrhythmias [5], implantation of a cardiac resynchronization therapydefibrillator (CRT-D) is appropriate for patients with a high risk of severe arrhythmias or heart failure [6, 7]. A CRT-D is used for patients with cardiac diseases such as $\mathrm{CS}$, dilated cardiomyopathy to restore the conduction abnormalities by coordinating the pump function of the left and right ventricles.

The point of perioperative management of patients with CS is to prevent arrhythmias and worsening of cardiac dysfunction. The key to successful anesthetic management of CS patients is understanding the characteristic features of this disease and implementing the

\section{Springer Open}

(c) The Author(s). 2020 Open Access This article is licensed under a Creative Commons Attribution 4.0 International License, which permits use, sharing, adaptation, distribution and reproduction in any medium or format, as long as you give appropriate credit to the original author(s) and the source, provide a link to the Creative Commons licence, and indicate if changes were made. The images or other third party material in this article are included in the article's Creative Commons licence, unless indicated otherwise in a credit line to the material. If material is not included in the article's Creative Commons licence and your intended use is not permitted by statutory regulation or exceeds the permitted use, you will need to obtain permission directly from the copyright holder. To view a copy of this licence, visit http://creativecommons.org/licenses/by/4.0/. 
proper settings of the CRT-D device. Currently, case reports about the anesthetic management of patients with CS are limited [8-12]. As a result, this case report aims to describe the perioperative management of a CS patient with an implanted CRT-D.

\section{Case presentation}

A 65-year-old male (height $165 \mathrm{~cm}$, weight $49 \mathrm{~kg}$ ) was scheduled for a laparoscopy-assisted total proctocolectomy for type 2 colon cancer. His medical history included CS for 2 years and ulcerative colitis for 20 years. The former condition was treated with $5 \mathrm{mg}$ of prednisolone, $2.5 \mathrm{mg}$ of enalapril, $12.5 \mathrm{mg}$ of spironolactone, 5 $\mathrm{mg}$ of bisoprolol fumarate, and $50 \mathrm{mg}$ of amiodarone, and the latter with $2400 \mathrm{mg}$ of mesalazine. A CRT-D device was implanted due to symptomatic non-sustained ventricular tachycardia occurring shortly after his CS diagnosis. Before the implantation, the QRS duration was $136 \mathrm{~ms}$ and his left ventricular ejection fraction (LVEF) was $30.0 \%$ using the modified Simpson method, and $35.2 \% 4$ months after the implantation. Although he experienced no firing of the defibrillator after device introduction, his cardiac function gradually declined to a New York Heart Association (NYHA) class III on admission. The CRT-D device was programmed in the dualchamber pacing (DDD) modality at a lower rate of 60 beats/min, with the checkup record revealing that $94 \%$ of the cardiac rhythm was dependent on the device. The electrocardiogram (ECG) presented a ventricular-paced rhythm with a heart rate of 75 beats/min. Preoperative transthoracic echocardiography showed overall left ventricular wall motion abnormalities with a LVEF of $32.0 \%$. Abnormal ventricular septal thinning, one of the main criteria for CS [13], was also detected (Fig. 1). In addition to CS, a positron emission tomographycomputed tomography (PET-CT) showed bilateral hilar lymphadenopathy and several nodules in the lungs indicative of pulmonary sarcoidosis, despite a lack of clinical pulmonary manifestations. Additional examinations, including laboratory testing, a spirogram, and a chest Xray, were within the normal range.

We selected general anesthesia combined with epidural anesthesia (Th11-12) for perioperative management of this patient. We maintained the usual prednisolone medication on the operation day and administered $100 \mathrm{mg}$ of hydrocortisone pre-operatively. The induction of anesthesia and the tracheal tube intubation were uneventful, using $100 \mu \mathrm{g}$ of fentanyl, $3 \mathrm{mg}$ of midazolam, and $30 \mathrm{mg}$ of rocuronium. Anesthesia was maintained with sevoflurane (1.0-1.5\%) and remifentanil $(0.1-0.3 \mu \mathrm{g} / \mathrm{kg} / \mathrm{min})$. In addition to standard monitoring, invasive arterial pressure via the left radial artery, central venous pressure via the right internal jugular vein, stroke volume index, cardiac index, stroke volume variation,

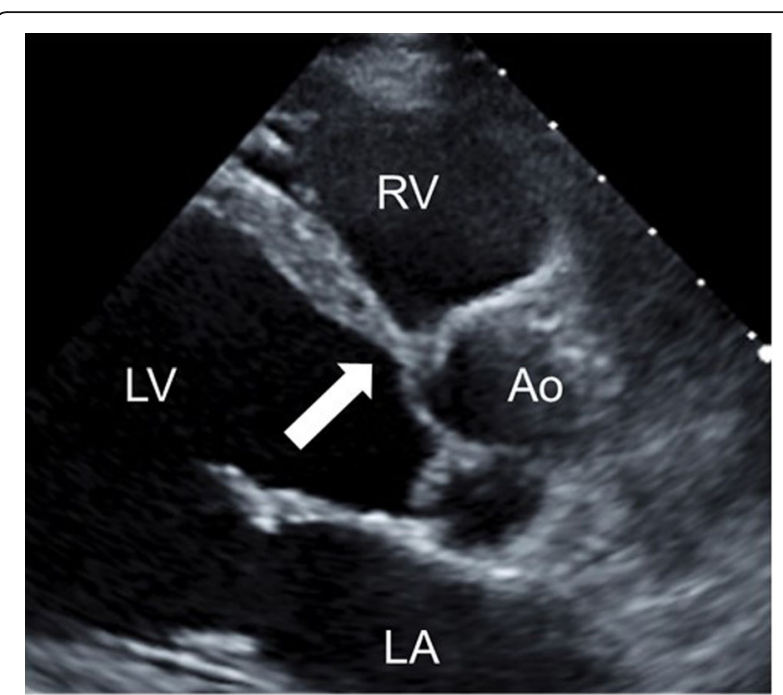

Fig. 1 Abnormal thinning of the basal ventricular septum. A parasternal long-axis transthoracic echocardiography view at the level of the aortic valve showing abnormal ventricular septal thinning with a minimal thickness of $4.4 \mathrm{~mm}$ (arrow). LA left atrium, $\mathrm{LV}$ left ventricle, RA right atrium, RV right ventricle, Ao aorta

systemic vascular resistance, and central venous oxygen saturation were monitored with the use of the FloTrac/ PreSep/EV1000 ${ }^{\mathrm{TM}}$ system (Edwards Lifesciences, Irvine, CA, USA). The modality of the CRT-D was unchanged except for its defibrillation function, which was deactivated before induction of anesthesia to avoid malfunctioning during surgery. Instead, defibrillation pads were placed on the patient and connected to another defibrillator in case of fatal arrhythmias.

As shown in Fig. 2, some hemodynamic fluctuations occurred during the course of the surgery, especially when the patient was intubated, the surgical procedure was started, the pneumoperitoneum was started, and the posture of the patient was changed. However, those changes were successfully managed with bolus administration of phenylephrine, continuous infusion of dopamine, bolus infusion of colloid, and/or titration of anesthetics, in accordance with the abovementioned monitoring. The total operation time was $8 \mathrm{~h}$ and 52 $\mathrm{min}$, and the total anesthesia time was $10 \mathrm{~h}$ and $47 \mathrm{~min}$. The total infusion volume was $2710 \mathrm{ml}$, and the total amount of bleeding and urine output were 108 and 1208 $\mathrm{ml}$, respectively. After the surgery, the defibrillation function was reactivated, and the patient was uneventfully extubated. His postoperative pain was successfully controlled with a continuous epidural infusion of $0.125 \%$ levobupivacaine $(5 \mathrm{ml} / \mathrm{h})$ that was started before the end of the surgery. The intensive cardiac monitoring was continued just before he was transferred from the intensive care unit to the ward, while continuous ECG and $\mathrm{SpO}_{2}$ monitoring were performed until postoperative 


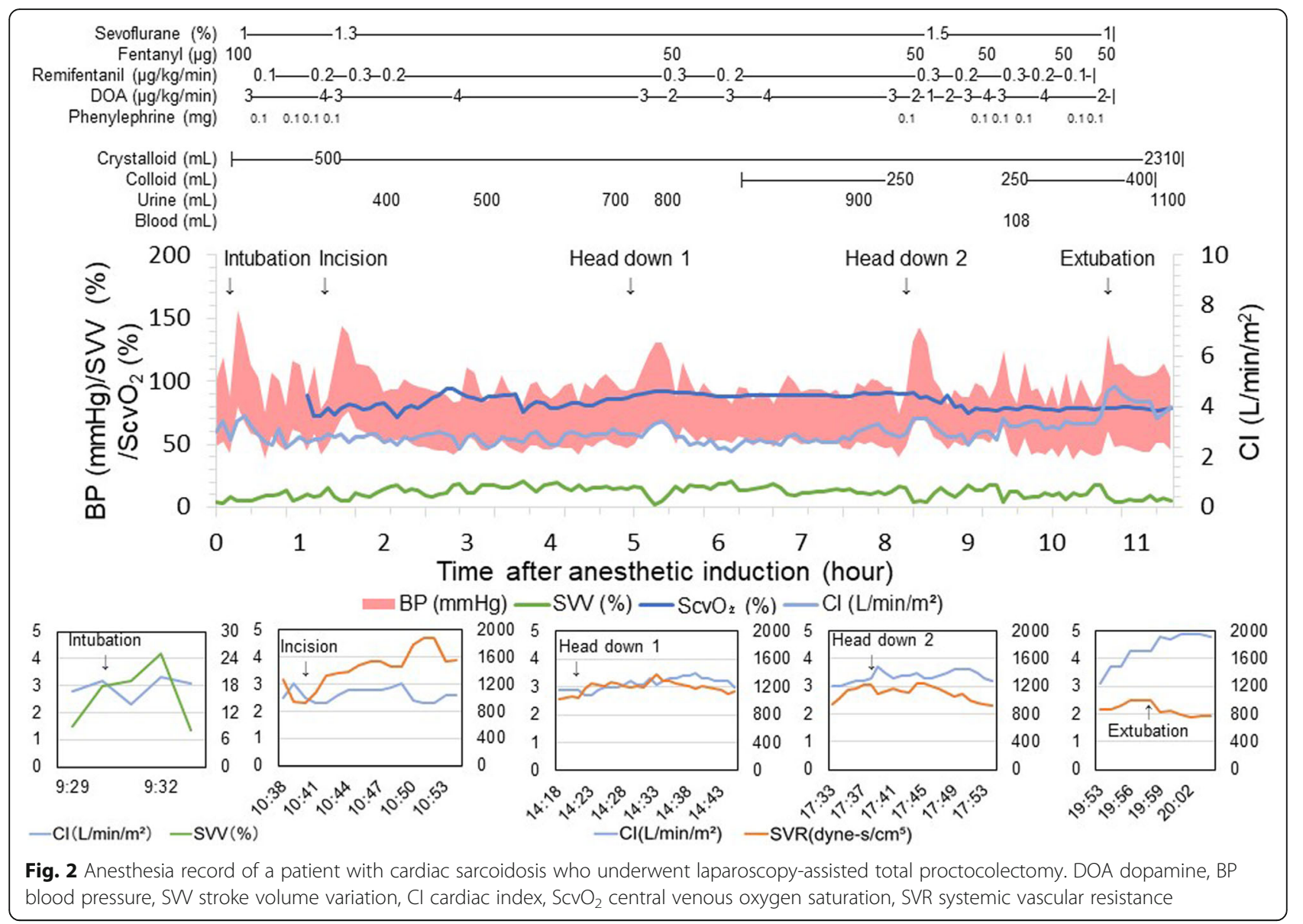

day (POD) 3. He was discharged on POD 24 without any deterioration of his cardiac condition.

\section{Discussion}

As far as we know, this is the first case report describing the anesthetic management of a CS patient with an implanted CRT-D. We accomplished safe anesthetic management by understanding the characteristic features of this disease, implementing the proper settings of the CRT-D device, and preventing progressive heart failure by using the FloTrac ${ }^{\mathrm{TM}} /$ PreSep/EV1000 ${ }^{\mathrm{TM}}$ system.

Racial differences in the incidence of CS have been reported, with Japanese patients more frequently reported to have the disease in comparison to Caucasian or African-American patients [2, 14, 15]. Cardiac involvement is reported clinically in $5 \%$ of sarcoidosis patients; however, autopsy and cardiovascular magnetic resonance studies have shown a higher percentage of subclinical cardiac involvement, ranging from 15 to $80 \%$, which accounts for the majority of sarcoidosis-related deaths [2, 3 , 14]. Clinical management of arrhythmias include the use of antiarrhythmics and/or the placement of an automatic ICD $[2,4]$. ICD placement is a class 1 recommendation for CS patients with spontaneous sustained ventricular arrhythmias, a previous cardiac arrest, or a LVEF $\leq 35 \%$ despite optimal medical therapy and a period of immunosuppression [5]. CRT placement is also considered for CS patients who are at risk for the development of heart failure [6, 7].

Case reports of anesthetic management for CS patients are limited. In one report, the CS patient had a pacemaker [10]; in another report, the patient had an ICD [11]; and in two other reports, the patients did not have any devices $[8,9]$. In another case, emergency introduction of a temporary pacemaker via the jugular vein was needed due to a complete atrioventricular block during surgery [12]. However, we could find no reports related to anesthetic management of CS patients with implanted CRT-Ds.

CRTs are used to correct conduction abnormalities by coordinating the pump functions of the left and right ventricles. However, when comparing a cohort of patients with CS with a cohort of patients with dilated cardiomyopathy, the response to CRT was lower, with a higher rate of major adverse cerebral and cardiovascular events (MACCE) [7]. Moreover, among CS patients, the occurrence of ventricular tachycardia/fibrillation (VT/ VF) was elevated [16]. These higher complication rates 
may be attributable to LV dysfunction due to sarcoid lesions and granulomas, as well as widely spreading fibrosis in the myocardium, which exceeded the benefit of CRT in CS patients [7]. In the present case, the patient's cardiac function had progressively worsened since CRTD implantation. Thus, clinicians should be aware that there is still a risk of cardiac compromise, even in the presence of a CRT-D, and especially in perioperative settings where many factors, including the stress response, fluid shifts, and hormonal changes, can have substantial influences on the heart and the whole body. Potential intraoperative problems related to CRT-Ds include electromagnetic interference (EMI) caused by surgical devices and the malfunctioning of the defibrillator. We maintained the DDD pacing mode throughout the operation. Shifting the pacing mode to asynchronous pacing, such as VOO, is useful for preventing EMIs; however, the VOO mode of a CRT-D cannot synchronize the left and right ventricles. In order to maintain cardiac output, it is desirable to continue with the synchronous pacing mode if possible.

Anesthetic strategies for patients with sarcoidosis have not clearly been determined due to a limited amount of published research, and no deteriorative anesthetic agents have been reported. In this patient, we chose to use sevoflurane because it has less of an effect on myocardial contractility [17] and is less likely to cause arrhythmias [18, 19]. Remifentanil, which has a direct negative chronotropic effect [20], was also safely used in this patient, partially due to the support of the CRT. Nevertheless, the long-term effect of anesthetic drugs on patients with sarcoidosis remains unknown, and further research should be conducted in this field. Continuous epidural anesthesia was used because we believed that reducing the postoperative afterload would be effective in preventing worsening of heart failure. On the other hand, we refrained from bolus administration intraoperatively because the reduction of the preload by epidural anesthesia would disrupt the hemodynamics of this patient.

This patient's laparoscopic surgery required a significant amount of time in the head-down and head-up positions. The head-down position increases the preload, and the head-up position decreases it. In order to avoid excessive preload and afterload, it was helpful to monitor the stroke volume variation (SVV) and the systemic vascular resistance (SVR) using the FloTrac/PreSep/ $\mathrm{EV} 1000^{\mathrm{TM}}$ system. Although the usefulness of dynamic parameters such as SVV in laparoscopic surgery are controversial, anesthesia time in this case was more than 10 $h$, which increased the importance of sequential hemodynamic monitoring for this patient.

In this patient, the only clinical manifestations of sarcoidosis were in the heart. However, clinicians should be wary about inherent limitations in the sarcoidosis diagnosis, including clinically undetectable inflammation in other organs or cardiac lesions that arise only as an original manifestation [14]. Thus, clinicians should be careful to examine all organs that can be affected by sarcoidosis. Indeed, although this patient did not show any symptoms, the PET-CT demonstrated lung involvement of the sarcoidosis, which can induce both a restrictive and an obstructive pulmonary disorder with wheezing and bronchial hyperreactivity, even in the absence of evident morphological abnormalities of the tracheobronchial tree [21]. Sarcoidosis of the upper respiratory tract, including laryngeal areas, should also be considered because it can occur in up to $5 \%$ of patients [22] and can cause difficult intubations, airway obstruction, and post-extubation croup.

We achieved safe anesthetic management of a patient with cardiac dysfunction caused by CS, who was previously implanted with a CRT-D. Although intraoperative cardiovascular system monitoring contributed to the successful anesthetic management, a detailed understanding of this patient's condition and his sarcoidosis diagnosis was indispensable for the proper perioperative management of this patient.

\section{Abbreviations \\ CS: Cardiac sarcoidosis; CRT-D: Cardiac resynchronization therapy-defibrillator; DDD: Dual-chamber pacing; ICD: Implantable cardioverter-defibrillator; NYHA: New York Heart Association; ECG: Electrocardiogram; LVEF: Left ventricular ejection fraction; PET-CT: Positron emission tomography- computed tomography; POD: Postoperative day; MACCE: Major adverse cerebral and cardiovascular events; VT/NF: Ventricular tachycardia/fibrillation}

\section{Acknowledgments}

We would like to thank Editage (www.editage.com) for the English language editing.

\section{Authors' contributions}

YK and AF contributed to the perioperative care of the patient. YK and $Y K$ wrote and revised the manuscript. AF and KY revised the manuscript. All authors read and approved the final version of the manuscript.

\section{Funding}

Not applicable.

\section{Availability of data and materials}

Data relevant to this case report are not available for public access because of patient privacy concerns but are available from the corresponding author on reasonable request.

Ethics approval and consent to participate

Not applicable.

\section{Consent for publication}

Written informed consent was obtained from the patient for the publication of this case report and the accompanying image.

\section{Competing interests}

The authors declare that they have no competing interests.

\section{Author details}

'Department of Anesthesiology and Critical Care Medicine, Kyushu University Hospital, Fukuoka, Japan. ${ }^{2}$ Operating Rooms, Kyushu University Hospital, Maidashi 3-1-1, Higashi-ku, Fukuoka 812-8582, Japan. ${ }^{3}$ Department of 
Anesthesiology and Critical Care Medicine, Graduate School of Medical Sciences, Kyushu University, Fukuoka, Japan. ${ }^{4}$ Medical information Center, Kyushu University Hospital, Fukuoka, Japan.

Received: 17 April 2020 Accepted: 27 May 2020

Published online: 06 June 2020

\section{References}

1. Valeyre D, Prasse A, Nunes $H$, Uzunhan $Y$, Brillet PY, Muller-Quernheim J. Sarcoidosis. Lancet. 2014;383(9923):1155-67.

2. Serei VD, Fyfe B. The many faces of cardiac sarcoidosis. Am J Clin Pathol 2020;153(3):294-302

3. Birnie DH, Nery PB, Ha AC, Beanlands RS. Cardiac sarcoidosis. J Am Coll Cardiol. 2016;68(4):411-21.

4. Lynch JP 3rd, Hwang J, Bradfield J, Fishbein M, Shivkumar K, Tung R. Cardiac involvement in sarcoidosis: evolving concepts in diagnosis and treatment. Semin Respir Crit Care Med. 2014;35(3):372-90.

5. Birnie DH, Sauer WH, Bogun F, Cooper JM, Culver DA, Duvernoy CS, et al. HRS expert consensus statement on the diagnosis and management of arrhythmias associated with cardiac sarcoidosis. Heart Rhythm. 2014;11(7): 1305-23.

6. Patel D, Trulock KM, Toro S, Grimaldi A, Gonzalez M, Moennich LA, et al. Effect of cardiac resynchronization therapy on left ventricular remodeling in patients with cardiac sarcoidosis. Am J Cardiol. 2019:123(2):329-33.

7. Yufu K, Kondo H, Shinohara T, Kawano K, Ishii Y, Miyoshi M, et al. Outcome of patients with cardiac sarcoidosis who received cardiac resynchronization therapy: comparison with dilated cardiomyopathy patients. J Cardiovasc Electrophysiol. 2017;28(2):177-81.

8. Imai M, Hayashi Y, Ono R, Shibata C, Mashimo T. Anesthesia for a patient with cardiac sarcoidosis. Masui. 2001;50(1):62-4.

9. Iwashita H, Matsukawa T, Ookawa I, lijima T, Sato I, Kumazawa T. Anesthetic management of a patient with cardiac sarcoidosis. Masui. 1995;44(12):1692-4

10. Miyoshi H, Kusunoki S, Kawamoto M. Total intravenous anesthesia for a patient with cardiac sarcoidosis associated with left ventricular dysfunction using remifentanil and propofol. Masui. 2010;59(6):715-8.

11. Nagata H, Sato Y, Oouchi S, Wakimoto M, Ishikawa K, Suzuki K. Anesthetic management for laparoscopic sigmoidectomy in a patient with impaired ventricular function caused by cardiac sarcoidosis. Masui. 2012;61(8):859-62.

12. Thomas DW, Mason RA. Complete heart block during anaesthesia in a patient with sarcoidosis. Anaesthesia. 1988;43(7):578-80.

13. Aggarwal NR, Snipelisky D, Young PM, Gersh BJ, Cooper LT, Chareonthaitawee P. Advances in imaging for diagnosis and management of cardiac sarcoidosis. Eur Heart J Cardiovasc Imaging. 2015;16(9):949-58.

14. Kusano KF, Satomi K. Diagnosis and treatment of cardiac sarcoidosis. Heart 2016;102(3):184-90.

15. Iwai K, Sekiguti M, Hosoda Y, DeRemee RA, Tazelaar HD, Sharma OP, et al. Racial difference in cardiac sarcoidosis incidence observed at autopsy. Sarcoidosis. 1994;11(1):26-31.

16. Kron J, Sauer W, Schuller J, Bogun F, Crawford T, Sarsam S, et al. Efficacy and safety of implantable cardiac defibrillators for treatment of ventricular arrhythmias in patients with cardiac sarcoidosis. Europace. 2013;15(3):347-54.

17. Kanaya N, Kawana S, Tsuchida H, Miyamoto A, Ohshika H, Namiki A. Comparative myocardial depression of sevoflurane, isoflurane, and halothane in cultured neonatal rat ventricular myocytes. Anesth Analg. 1998:87(5):1041-7.

18. Jakobsen CJ, Berg H, Hindsholm KB, Faddy N, Sloth E. The influence of propofol versus sevoflurane anesthesia on outcome in 10,535 cardiac surgical procedures. J Cardiothorac Vasc Anesth. 2007;21(5):664-71.

19. Hemmerling TM, Minardi C, Zaouter C, Noiseux N, Prieto I. Sevoflurane causes less arrhythmias than desflurane after off-pump coronary artery bypass grafting: a pilot study. Ann Card Anaesth. 2010;13(2):116-22.

20. Gurkan A, Birgul Y, Ziya K. Direct cardiac effects in isolated perfused rat hearts of fentanyl and remifentanil. Ann Card Anaesth. 2005:8(2):140-4.

21. Bonifazi M, Gasparini S, Alfieri V, Renzoni EA. Pulmonary sarcoidosis. Semin Respir Crit Care Med. 2017;38(4):437-49.

22. Baughman RP, Lower EE, Tami T. Upper airway. 4: Sarcoidosis of the upper respiratory tract (SURT). Thorax. 2010;65(2):181-6.

\section{Publisher's Note}

Springer Nature remains neutral with regard to jurisdictional claims in published maps and institutional affiliations.

\section{Submit your manuscript to a SpringerOpen ${ }^{\circ}$ journal and benefit from:}

- Convenient online submission

- Rigorous peer review

- Open access: articles freely available online

- High visibility within the field

- Retaining the copyright to your article

Submit your next manuscript at $\boldsymbol{\nabla}$ springeropen.com 